\title{
Hypoxaemia during cardiopulmonary bypass
}

\author{
A. L. MUIR and I. A. DAVIDSON \\ Departments of Medicine and Anaesthetics, The University of Edinburgh and \\ The Royal Infirmary of Edinburgh
}

\begin{abstract}
Blood oxygenation was studied in patients undergoing cardiopulmonary bypass using the RyggKyvsgaard bubble oxygenator. Oxygenation was satisfactory in perfusions carried out at normothermia and during hypothermia. During the rewarming phase of hypothermic perfusions hypoxaemia occurred. This could be prevented by a ganglion blocking agent (trimetaphan) given during the cooling phase.
\end{abstract}

For cardiopulmonary bypass during open-heart surgery we use a bubble oxygenator and a technique of haemodilution and moderate hypothermia. During the course of routine perfusion we have observed arterial desaturation in a number of patients and in five patients the desaturation was marked $\left(\mathrm{SaO}_{2}<85 \%\right)^{1}$. The low arterial oxygen saturations occurred mainly in the rewarming period. This report is of an investigation into this arterial hypoxia occurring during hypothermic cardiopulmonary bypass.

\section{METHODS}

PERFUSION TECHNIQUE As an oxygenator we use a Rygg-Kyvsgaard disposable bubble oxygenator. Reports of its clinical use and oxygenating capacity have been published (Frederiksen et al. 1963; Rygg, Frederiksen, and Jorgensen, 1963). Venous blood from the right atrium or both venae cavae is gravity fed into the oxygenator. Inflow gas consisting of $98 \%$ $\mathrm{O}_{2}$ and $2 \% \mathrm{CO}_{2}$ is delivered to the bubble oxygenator at a flow rate one and a half times the blood flow rate through the circuit. After oxygenation and defoaming the blood is returned to the aorta by an occlusive roller pump.

The whole circuit is primed with approximately 1.5 litres of Ringer lactate, the volume being adjusted to give a haematocrit of 25 to $30 \%$ on haemodilution. After the start of the perfusion, the patient's temperature, monitored by oesophageal and nasopharyngeal thermistors, is reduced to approximately $30^{\circ} \mathrm{C}$ using a heat exchanger in the circuit. Towards the end of the perfusion the body temperature is returned to $37^{\circ} \mathrm{C}$. We have used hypothermia so that we could reduce blood flow rates and have a longer safe period if total circulatory arrest was required. How-

'The respiratory symbols employed follow the recommendations of Pappenheimer, J. R. and associates, Fed. Proc., 9, 602, 1950. $P$ indicates partial pressure, $S$ haemoglobin saturation, $a, v, \bar{v}$ arterial, venous, and mixed venous blood respectively. ever, during the studies reported here, the flow rate was kept constant at $2 \cdot 41 . / \mathrm{min} / \mathrm{m}^{2}$ body surface area.

During the perfusion additional Ringer lactate or whole blood is added if the level in the blood reservoir falls. The $\mathrm{pHa}$ and $\left(\mathrm{HCO}_{3}\right)$ of patients' blood is monitored and, if needed, appropriate changes in $\mathrm{CO}_{2}$ concentration in the inflow gas are made or sodium bicarbonate is added.

PATIENTS AND PLAN OF INVESTIGATION The observations were made on 29 adult patients undergoing mitral or aortic valve replacement. Throughout all the studies the perfusion flow rate was kept constant at $2.41 . / \mathrm{min} / \mathrm{m}^{2}$.

In 12 patients extracorporeal circulation was conducted in our standard hypothermic technique. In a further 10 patients perfusion was performed at normothermia, but in all other aspects the perfusion technique was unchanged.

A further seven patients were perfused using the standard hypothermic perfusion, but in addition these patients received a ganglion-blocking agent (trimetaphan, $25 \mathrm{mg}$ ) during the cooling phase. Again the flow rate was kept constant and additional doses of trimetaphan were given if the mean arterial pressure rose above $50 \mathrm{mmHg}$.

During the course of these studies the manufacturers of the oxygenator made minor changes in the bubbling system. Of our 10 normothermic perfusions, 5 were carried out using the unmodified oxygenator and 5 perfusions were performed using the new oxygenator. The hypothermic perfusions with and without trimetaphan were carried out using the unmodified oxygenator.

Blood samples were obtained from the venous (inflow) and arterial (outflow) ends of the oxygenator. In the hypothermic perfusion blood samples were obtained during established hypothermia and at every $2^{\circ} \mathrm{C}$ increment in body temperature during the rewarming phase. In the normothermic perfusions blood samples were obtained at 2-minute intervals 
for the first 10 minutes of perfusion and then at 10 minute intervals.

LABORATORY TECHNIQUES Blood samples were analysed as soon as possible after withdrawal. All blood samples were analysed at $37^{\circ} \mathrm{C}$. $\mathrm{Po}_{2}$ and $\mathrm{PCO}_{2}$ were measured in a combined cuvette instrument (IL Model 113) and $\mathrm{pH}$ was determined using the ultra micro $\mathrm{pH}$ electrode of the same system. The accuracy of this instrument in our laboratory has been described (Flenley, Millar, and Rees, 1967). Corrections from the temperature at which the $\mathrm{Po}_{2}, \mathrm{PCO}_{2}$, and $\mathrm{pH}$ were measured to the temperature at which the samples were withdrawn from the oxygenator were made using the data of Severinghaus (1966). The same data were used to derive oxygen saturations. In a number of cases oxygen saturations were also measured directly using a haemoreflector technique. Oxygen-carrying capacity of the blood was measured using a spectrophotometric technique.

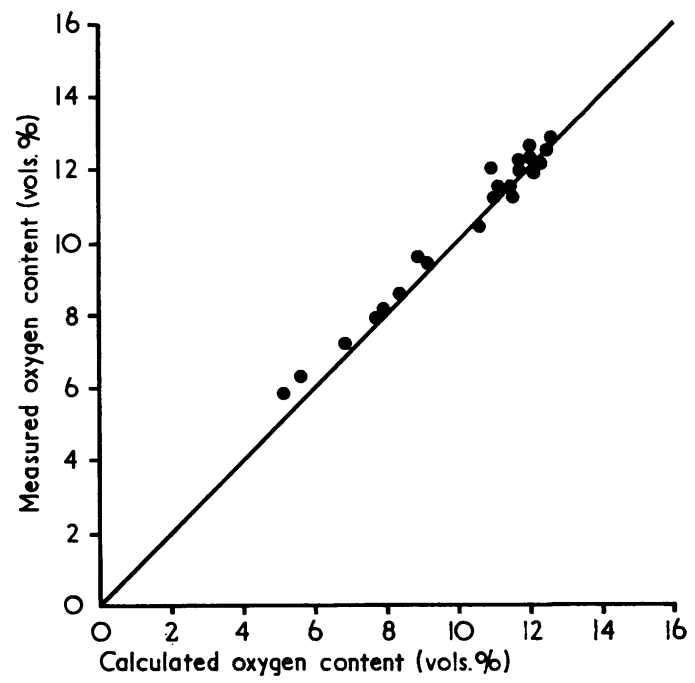

FIG. 1. Oxygen content derived from $\mathrm{Po}_{2}$ and $\mathrm{pH}$ using the data of Severinghaus (1966) plotted against oxygen content measured by the method of Van Slyke and Neill (1924).
In 22 of the 29 patients one determination of total oxygen content was made using the method of Van Slyke and Neill (1924). This sample was withdrawn at varying temperatures and at the same time a sample was withdrawn for estimation of $\mathrm{Po}_{2}$ and oxygen-carrying capacity. From the oxygen tension and capacity a calculated oxygen content was obtained. The relationship between calculated oxygen content and measured oxygen content is shown in Figure 1.

\section{RESULTS}

Two patients who had a standard hypothermic perfusion and one patient who had a hypothermic perfusion with trimetaphan had low arterial oxygen tensions even during hypothermia. The results from these patients are shown in Table I but as they were quite different from those of the other patients they have been excluded from further analysis.

\section{T A B L E I}

PATIENTS EXCLUDED FROM STUDY: RESULTS AT HYPOTHERMIA AND AFTER REWARMING

\begin{tabular}{|c|c|c|c|c|c|}
\hline Patient & $\underset{\left({ }^{\circ} \mathrm{C}\right)}{\text { Temp. }}$ & $\underset{(\mathrm{mmHg})}{\mathrm{PaO}_{\mathbf{g}}}$ & $\underset{\%}{\mathrm{SaO}_{2}}$ & $\underset{\text { (mmḦ) }}{\text { Pṽo }_{\mathbf{z}}}$ & $\underset{\%}{\text { Sv̄o, }}$ \\
\hline $\begin{array}{l}\text { A.F. } \\
\text { McK. } \\
\text { U.N. }\end{array}$ & $\begin{array}{l}30 \\
37 \\
34 \\
37 \\
28 \\
37\end{array}$ & $\begin{array}{l}45 \\
46 \\
45 \\
64 \\
41 \\
49\end{array}$ & $\begin{array}{l}95 \\
80 \\
81 \\
89 \\
77 \\
78\end{array}$ & $\begin{array}{l}22 \\
24 \\
22 \\
24 \\
23 \\
29\end{array}$ & $\begin{array}{l}63 \\
38 \\
35 \\
32 \\
40 \\
45\end{array}$ \\
\hline
\end{tabular}

STANDARD HYPOTHERMIC PERFUSION (Table II) At moderate hypothermia $\left(25\right.$ to $\left.32^{\circ} \mathrm{C}\right)$ arterial oxygen tensions ranged from 108 to $323 \mathrm{mmHg}$. These levels of oxygen tensions ensured that in all patients the blood leaving the oxygenator was fully saturated. The mean saturation of the venous blood returned from the patients was $80 \%$ and in only one patient was the venous saturation less than $70 \%$. Due to the haemodilution technique the oxygen-carrying capacity of the blood was reduced (mean $11.36 \pm$ S.E.M. 0.54 vol. \%).

T A B L E I I

STANDARD HYPOTHERMIC PERFUSION: RESULTS IN 10 PATIENTS

\begin{tabular}{|c|c|c|c|c|c|c|c|c|}
\hline & $\mathrm{PaO}_{2}$ & $\mathrm{Paco}_{2}$ & $\left(\mathbf{H}^{+}\right)$ & Sao, & $\mathrm{P}_{\mathbf{v}} \mathbf{O}_{2}$ & Sर̃o, & Cap. & A-V Diff. \\
\hline $\begin{array}{l}\text { Cold } \\
\text { Mean } \\
\text { S.E.M. }\end{array}$ & $\begin{array}{r}233 \\
\pm 23\end{array}$ & $\begin{array}{r}44 \\
\pm 2\end{array}$ & $\begin{array}{c}44 \\
\pm 1.9\end{array}$ & $\begin{array}{l}100 \\
\pm 0\end{array}$ & $\begin{array}{c}32 \\
\pm 1\end{array}$ & $\begin{array}{r}80 \\
\pm 3\end{array}$ & $\begin{array}{r}11.36 \\
\pm 0.54\end{array}$ & $\begin{array}{r}2.35 \\
\pm 0.31\end{array}$ \\
\hline $\begin{array}{l}\text { After rewarming } \\
\text { Mean } \\
\text { S.E.M. }\end{array}$ & $\begin{array}{r}73 \\
\pm 4\end{array}$ & $\begin{array}{r}59 \\
\pm 2\end{array}$ & $\begin{array}{r}51 \\
\pm 2\end{array}$ & $\begin{array}{r}92 \\
\pm 1\end{array}$ & $\begin{array}{r}33 \\
\pm 2\end{array}$ & $\begin{array}{r}56 \\
\pm 4\end{array}$ & $\begin{array}{r}11.49 \\
\pm 0.37\end{array}$ & $\begin{array}{c}4.22 \\
\pm 0.38\end{array}$ \\
\hline
\end{tabular}

Tensions in $\mathrm{mmHg}$. $\left(\mathrm{H}^{+}\right)$hydrogen ion concentrations in $\mu \mathrm{mEq} / \mathrm{l}$. Saturations as percent. Cap=oxygen carrying capacity in ml oxysen per $100 \mathrm{ml}$ blood. A-V Diff. = arteriovenous oxygen difference in $\mathrm{ml}$ per $100 \mathrm{ml}$ blood. S.E.M. $=$ standard error of the mean. 


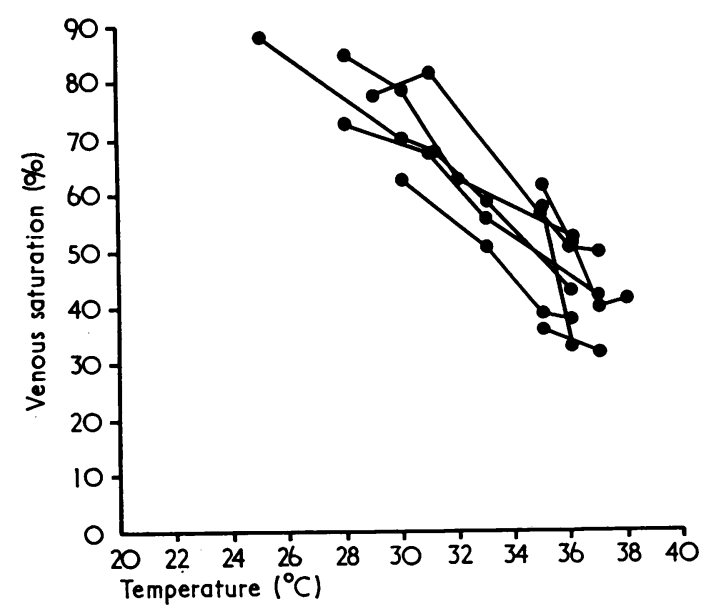

FIG. 2. Venous oxygen saturations on rewarming from hypothermia in patients who had the standard hypothermic perfusion.

After rewarming the mean arterial oxygen tension fell to $73 \mathrm{mmHg}$. The lowest oxygen tension was $57 \mathrm{mmHg}$ at $37^{\circ} \mathrm{C}$ in a patient who had had an arterial oxygen tension of $287 \mathrm{mmHg}$ at $30^{\circ} \mathrm{C}$. Arterial oxygen saturations ranged from 83 to $97 \%$. There was a progressive fall in venous oxygen saturation during rewarming (Fig. 2), and when the rewarming was completed venous oxygen saturation was $56 \pm 4 \%$. There had been no significant change in the degree of haemodilution during rewarming so that arteriovenous oxygen difference had nearly doubled. Throughout the perfusion the pump flow rate had been kept constant.

NORMOTHERMIC PERFUSION (Table III) After the start of the perfusion there was an immediate fall in arterial oxygen tensions and saturations in all patients (Fig. 3). The mean venous oxygen saturation was low at the start of the perfusion $(52 \pm 2 \cdot 3 \%)$. In a number of patients this became even lower after 2 to 3 minutes of perfusion. In two patients arterial oxygen tensions remained below $50 \mathrm{mmHg}$ for over 6 minutes. There was a gradual increase in arterial and venous oxygen

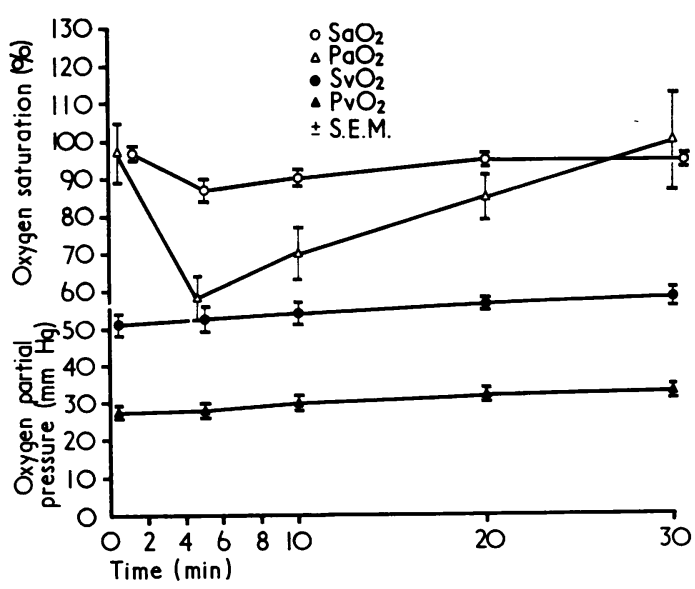

FIG. 3. Arterial and venous oxygen tensions and saturations during normothermic perfusion. Mean of 10 patients \pm standard error of the mean.

tensions and saturations over the following 20 minutes of perfusion. Throughout the period of increase in blood oxygenation, arterial blood was approximately $35 \%$ more saturated than the venous blood. This was a relatively constant difference in all patients and seemed independent of minor changes in oxygen-carrying capacity of the perfusing fluid.

There was no difference between the performance of the modified and unmodified bubble oxygenators.

HYPOTHERMIC PERFUSION WITH TRIMETAPHAN The mean values obtained whilst at moderate hypothermia and after rewarming in those patients treated with trimetaphan are presented in Table IV.

COMPARISON OF RESULTS The values for arterial and venous oxygen saturations obtained in all three groups are contrasted in Figure 4. While there was no significant difference between patients treated with and without trimetaphan during hypothermia, after rewarming arterial oxygen saturations were significantly higher in

T A B L E I I I

NORMOTHERMIC PERFUSION: RESULTS IN 10 PATIENTS

\begin{tabular}{l|c|c|c|c|c|c|c|c}
\hline & Pao, & Paco, & $\left(\mathbf{H}^{+}\right)$ & Sao, & Pṽo, & Sṽo, & Cap. & A-V Diff. \\
\hline Mean & 104 & 42 & 43 & 97 & 33 & $\begin{array}{c}58 \\
\pm 0.7\end{array}$ & $\begin{array}{r}11.25 \\
\pm 0.43\end{array}$ & $\begin{array}{r}4.22 \\
\pm 0.15\end{array}$ \\
\hline
\end{tabular}

Units and abbreviations as in Table II. 
T A B L E I V

HYPOTHERMIC PERFUSION WITH TRIMETAPHAN: RESULTS IN 6 PATIENTS

\begin{tabular}{|c|c|c|c|c|c|c|c|c|}
\hline & $\mathrm{PaO}_{2}$ & $\mathrm{PaCO}_{2}$ & $\left(\mathbf{H}^{+}\right)$ & $\mathrm{SaO}_{2}$ & $\mathrm{P}_{\bar{v}} \mathrm{O}_{2}$ & Sv̄o, & Cap. & A-V Diff. \\
\hline $\begin{array}{l}\text { Cold } \\
\text { Mean } \\
\text { S.E.M. }\end{array}$ & $\begin{array}{r}280 \\
\pm 50\end{array}$ & $\begin{array}{r}32 \\
\pm 3\end{array}$ & $\begin{array}{r}34 \\
\pm 2\end{array}$ & $\begin{array}{l}100 \\
\pm 0\end{array}$ & $\begin{array}{r}33 \\
\pm 1\end{array}$ & $\begin{array}{r}85 \\
\pm 2\end{array}$ & $\begin{array}{r}12.77 \\
\pm 0.69\end{array}$ & $\begin{array}{r}2.84 \\
\pm 1.82\end{array}$ \\
\hline $\begin{array}{l}\text { After rewarming } \\
\text { Mean } \\
\text { S.E.M. }\end{array}$ & $\begin{array}{l}162 \\
\pm 5\end{array}$ & $\begin{array}{r}45 \\
\pm 4\end{array}$ & $\begin{array}{r}47 \\
\pm 2\end{array}$ & $\begin{array}{r}97 \\
\pm 2\end{array}$ & $\begin{array}{r}39 \\
\pm 3\end{array}$ & $\begin{array}{r}66 \\
\pm 4\end{array}$ & $\begin{array}{r}13.67 \\
\pm 0.87\end{array}$ & $\begin{array}{r}\mathbf{4 . 3 0} \\
\pm \mathbf{0 . 6 8}\end{array}$ \\
\hline
\end{tabular}

Units and abbreviations as in Table II.

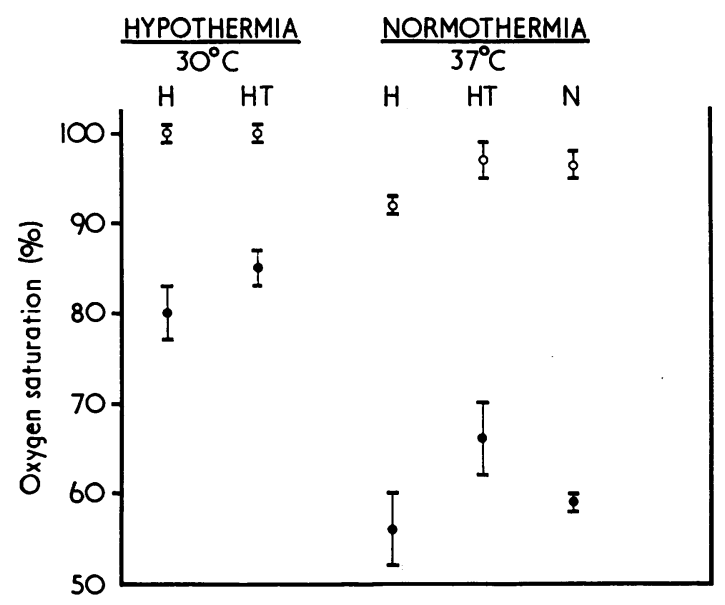

FIG. 4. Arterial and venous oxygen saturations at hypothermia and normothermia in patients who had hypothermic perfusions $(H)$, hypothermic perfusions with trimetaphan $(H T)$, and normothermic perfusions $(N)$. Results plotted as mean \pm standard error of the mean from the data of Tables $I I, I I I$, and IV. $\bigcirc$ arterial; $\bullet$ venous.

the group treated with trimetaphan $(P<0.05)$ as were arterial oxygen tensions $(P<0.01)$. Venous oxygen saturations after rewarming did not fall as much in the trimetaphan treated group although the difference did not achieve statistical significance. In all patients in all three groups, there was a significant correlation between arterial and venous oxygen saturations at normothermia $(r=0.581, n=26, P<0.01)$.

\section{DISCUSSION}

Bubble oxygenators have been used extensively in extracorporeal circulation for open-heart surgery. They are easy to operate and have a small priming volume; manufacturing costs are low and the equipment can be disposable. However, they do have a number of short-comings. Haemolysis may occur at a greater rate than with other types of oxygenator (Clowes, 1960). During our perfusions the plasma haemoglobin increased by approximately $1 \mathrm{mg} / 100 \mathrm{ml}$ per minute of perfusion. In addition, bubble oxygenators require adequate defoaming devices and the defoaming action may become unreliable in long perfusions (Galletti, 1967).

Rygg et al. (1963) reported that in an in vitro study using ox blood adequate oxygenation occurred with the Rygg-Kyvsgaard bubble oxygenator. The same group also reported its successful use in prolonged extracorporeal circulation (Frederiksen et al., 1963). Detailed examination, however, of its in vivo oxygenating capacity was not made.

Using a similar bubble oxygenator (Travenol U-130) Burbank, Ferguson, and Burford (1966) performed an in vitro perfusion experiment. They demonstrated that this type of oxygenator could be limited by unusually low oxygen saturation of the venous blood and that the single passage oxygenating capacity was fixed at 35 to $40 \%$.

Apart from the three abnormal cases (Table I), we found that at moderate hypothermia there was always adequate arterial oxygenation. During rewarming arterial oxygen tensions fell and, in a number of patients, the low arterial oxygen tensions at normothermia were associated with arterial oxygen desaturation. As all oxygenation was being supplied by the bubble oxygenator, its function must be regarded as inadequate.

One possibility is that the oxygenator cannot supply the oxygen demands of a patient at normal temperature. Adequate oxygenation was, however, obtained in perfusions undertaken at normothermia, although the time taken to achieve oxygenation was often prolonged. There was a relatively constant relationship between the levels of arterial and venous oxygen saturations with the arterial blood $35 \%$ more saturated than 
the venous blood. In this respect the in vivo performance of the Rygg-Kyvsgaard bubble oxygenerator is similar to the in vitro performance of the Travenol U-130 described by Burbank and his colleagues (1966). They had predicted from their experimental work that venous blood delivered to the oxygenator with saturations below about $55 \%$ would be returned to the patient incompletely oxygenated. It is in such conditions of venous desaturation that we have encountered arterial hypoxia.

Venous desaturation at the start of perfusion is almost invariable. This is presumably due to the low cardiac output at this time which has been noted in animal studies (Cordell, Spencer, and Meredith, 1960 ; Rowen, Viles, and Ankeney, 1960). Several factors probably contribute to this low output, including handling of the heart, the presence of cannulae, a degree of blood loss, and the underlying cardiac pathology.

Venous desaturation may also occur during cardiopulmonary bypass due to the addition of stored blood. Our preliminary studies had shown that the addition of $500 \mathrm{ml}$ of stored blood reduced arterial and venous oxygen tensions for a period of 2 to 3 minutes. For this reason blood samples were not taken until at least 5 minutes after the addition of stored blood.

Once adequate perfusion is achieved, venous oxygen saturation does not usually fall below $60 \%$ (Clowes, 1960). Practical experience in many centres has shown that a flow rate of 2.4 $1 . / \mathrm{min} / \mathrm{m}^{2}$ provides adequate oxygenation and that during hypothermia flow rates can be reduced below this level (Clowes, 1967 ; Cheng, et al., 1959). In a preliminary study we had altered flow rate with little effect on arterial oxygenation except when the flow rate was severely reduced. This is in agreement with the findings of Paneth and his colleagues (1957) who found in dogs that, provided the flow rate was above $1.21 . / \mathrm{min} / \mathrm{m}^{2}$, oxygen consumption was constant. In addition, within the variation in haematocrit in our patients, there was no association between haematocrit and hypoxia.

During hypothermia venous blood was usually more than $80 \%$ saturated; however, in the rewarming period, venous desaturation became marked with levels in some patients below $45 \%$. Theye and Kirklin (1963), reporting on the performance of a vertical film oxygenator, noted venous oxygen saturations of 79 to $92 \%$ at $30^{\circ} \mathrm{C}$. During the rewarming phase the venous oxygen saturations of some patients fell below $60 \%$. Arterial oxygenation, however, was always adequate, presumably because their film oxygenator had sufficient reserve capacity to cope with such desaturated blood.

Our results have shown that perfusion flow rates as assessed by oxygenation were adequate at hypothermia and during normothermic perfusions ; however, in the rewarming phase desaturation occurs. It is possible that at this time circulation is being re-established to areas underperfused during the hypothermic period. Alterations in vascular tone occur during cardiopulmonary bypass (Cordell et al., 1960 ; Sanger et al., 1960). These changes could produce regional variations in flow with some areas receiving a reduced flow and being inadequately cooled. The effects of this would not appear until the rewarming period when affected areas would return markedly desaturated blood. If this increased vascular tone could be abolished it should be possible to avoid hypoxia resulting from this cause. We chose to use trimetaphan, a ganglion-blocking agent which has been widely used to produce controlled hypotension in surgery, because of its short duration of action. Those patients treated with trimetaphan showed smaller falls in venous oxygen saturations during rewarming, and arterial desaturation did not occur. The findings of Taguchi and his colleagues (1967) that patients treated with the alpha adrenergic blocking drug, phenoxybenzamine, prior to cardiopulmonary bypass are less likely to develop a metabolic acidosis parallels our work.

It is difficult to explain the failure to produce adequate oxygenation at hypothermia and normothermia in the three patients excluded from the detailed analysis. A possible explanation is that in a small number of oxygenators the bubbling system is faulty but we have no direct proof of this.

We should like to thank Mr. Andrew Logan, Mr. R. J. M. McCormack, and Mr. P. R. Walbaum, whose patients we studied; Dr. C. F. Hider, who anaesthetized most of the patients; and Professor K. W. Donald for the provision of laboratory facilities.

\section{REFERENCES}

Burbank, A., Ferguson, T. B., and Burford, T. H. (1966). Disposable bubble oxygenator: experimental studies of its performance. Arch. Surg., 93, 660.

Cheng, H. C., Kusunoki, T., Bosher, L. H. Jr., McElvein, R. B., and Blake, D. A. (1959). A study of oxygen consumption during extracorporeal circulation. Trans. Amer. Soc. artif. intern. Org., 5, 273.

Clowes, G. H. A. Jr. (1960). Extracorporeal maintenance of circulation and respiration. Physiol. Rev., 40, 826. 
(1967). In Cardiac Surgery, edited by J. C. Norman, p. 9. Butterworths, London.

Cordell, A. R., Spencer, M. P., and Meredith, J. H. (1960). Studies of peripheral vascular resistance associated with total cardiopulmonary bypass. I. Peripheral resistance under condition of normothermia and normotension. J. thorac. cardiovasc. Surg., 40, 421.

Flenley, D. C., Millar, J. S., and Rees, H. A. (1967). Accuracy of oxygen and carbon dioxide electrodes. Brit. med. $J$. 2, 349.

Frederiksen, T., Rosen, J., Rygg, I. H., Christensen, E., and Therkelsen, F. (1963). Prolonged extracorporeal circulation. Thorax, 18, 158.

Galletti, P. M. (1967). In Cardiac Surgery, edited by J. C. Norman, p. 66. Butterworths, London.

Paneth, M., Sellers, R., Gott, V. L., Weirich, W. L., Allen, P., Read, R. C., and Lillehei, C. W. (1957). Physiologic studies upon prolonged cardiopulmonary by-pass with the pump-oxygenator with particular reference to (1) Acid-base balance (2) Siphon caval drainage. J. thorac. Surg., 34, 570.

Rowen, H., Viles, P., and Ankeney, J. L. (1960). The effect of total body perfusion upon cardiac output and vascular resistance. J. thorac. caridovasc. Surg., 40, 529.
Rygg, I. H., Frederiksen, T., and Jørgensen, M. (1963). Gas exchange in the Rygg-Kyvsgaard bubble oxygenator. Thorax. 18, 220.

Sanger, P. W., Robicsek, F., Taylor, F. H., Rees, T. T., and Stam, R. E. (1960). Vasomotor regulation during extracorporeal circulation and open-heart surgery. J. thorac. cal diovasc. Surg., 40, 355.

Severinghaus, J. W. (1966). Blood gas calculator. J. appl. Physiol., 21, 1108.

Taguchi, K., Matsuura, Y., Nakai, H., Nakamura, S., Yoshizaki, E., and Yokoyama, T. (1967). Clinical use of Dibenzyline in open heart surgery with extracorporeal circulation-Observation on the effects of Dibenzyline on acid-base balance. Hiroshima J. med. Sci., 16, 115.

Theye, R. A., and Kirklin, J. W. (1963). Vertical film oxygenator performance at $30^{\circ} \mathrm{C}$. and oxygen levels during rewarming. Surgery, 54, 569.

Van Slyke, D. D., and Neill, J. M. (1924). The determination of gases in blood and other solutions, by vacuum extraction and manometric measurement. J. biol. Chem., 61, 523. 